\title{
TEORIAS DA INTERPRETAÇÃO: FUNDAMENTOS PSICOLÓGICOS E FILOSÓFICOS
}

\author{
Luciana Cesconetto Fernandes da Silva ${ }^{I}$
}

\begin{abstract}
Resumo
As teorias teatrais trazem implícita ou explicitamente uma noção de personalidade, de emoção e de imaginação que lhes possibilita compreender o ator, o trabalho do ator e o personagem. Estas noções formam o fundamento psicológico de uma teoria teatral. Identificar este fundamento é imprescindível para o professor de teatro que se preocupe com as conseqüências de suas ações como educador. Trata-se de um primeiro passo para o posicionamento crítico acerca destas teorias.
\end{abstract}

Palavras-chave: ator, interpretação teatral, psicologia da interpretação.

\begin{abstract}
Implicitly or explicitly, theatrical theories make use of conceptions of personality, emotion and imagination that make it possible to understand the actor, the actor's work and the character. These conceptions form the psychological substrate of any theatrical theory. In order to teach theater in a responsible way, it is mandatory to identify this foundation. This is the first step for having a critical view about these theatrical theories.
\end{abstract}

Keywords: actor, theatrical interpretation, psychology of interpretation.

\section{Teoria da interpretação teatral: uma área a ser explorada}

Quando temos por objetivo formar professores de teatro, temos que pensar na formação do professor-artista-cidadão, um sujeito que domine, no que diz respeito ao trabalho do ator, além de técnicas e métodos de interpretação, a contextualização destes. Não se trata somente de situá-los historicamente, mas proporcionar um conhecimento das bases filosóficas e/ou psicológicas que fundamentam estas perspectivas teóricas. Estes conhecimentos compõem o que poderíamos chamar de teoria da interpretação: “...há a necessidade do auxílio de uma disciplina que ajude os alunos a entender melhor o seu próprio trabalho. Com efeito, o ensino de interpretação precisa ser sistematizado através de uma disciplina que trate de questões ligadas à teoria e à história da interpretação" (FREITAS, 1998, p. 199).

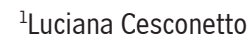
Fernandes da Silva é graduada em Licenciatura em Educação Artística - Habilitação Artes Cênicas - pela UDESC (1992); mestre em Teatro e Artes do Espetáculo pela Universidade de Paris III - Sorbonne Nouvelle (2003) e doutoranda em Estudos Teatrais também pela Universidade de Paris III. Atualmente é professora assistente do Departamento de Música e Artes Cênicas da Universidade Federal de Pelotas - UFPel. 
O aluno, futuro professor de teatro, deve ser situado perante o que vai aprender para se lançar com confiança ou se lançar com reservas, porém consciente desta atitude, desta escolha, pois sabe dos limites daquela teoria, até onde se identifica ou não com ela.

É no intuito de contribuir para este esclarecimento que propomos o presente estudo. Identificar os fundamentos psicológicos de alguns diretorespedagogos do século $\mathrm{XX}$, criando um subsídio didático que auxilie no posicionamento crítico do aluno e do professor perante o ensino/aprendizagem de algumas teorias de interpretação teatral. Escolhemos alguns reformadores do teatro do século XX, optando pelos que deram atenção especial ao trabalho do ator e que têm maior relevância no ensino da interpretação no país. Assim sendo, abordaremos as propostas de Constantin Stanislavski, Vsevolod Meyerhold, Antonin Artaud, Jerzy Grotowski e Eugenio Barba. Trataremos neste artigo de identificar as bases psicológicas e filosóficas destas teorias teatrais. A crítica será feita em outro momento e poderá constituir o objeto de estudo de outro artigo.

\section{Teorias do teatro e fundamentações psicológicas}

\section{Constantin Stanislavski (1863 - 1938)}

Identificam-se duas fases no que se refere à formação do ator em Stanislavski. A primeira caracteriza-se pela ênfase na análise psicológica do personagem, ao estudo reflexivo do texto, das circunstâncias dadas, das emoções dos personagens antes de uma abordagem com experiência corporal. $\mathrm{O}$ ator encontra reflexivamente os objetivos, a linha de ação, o subtexto, a memória emotiva; seleciona uma partitura de emoções (o que Stanislavski chama muitas vezes de sentimentos) que depois serão exteriorizados quando o ator for trabalhar fisicamente; imagina $\mathrm{o}$ personagem, observa fotografias, pessoas da realidade que o cercam; seleciona as imagens que cabem ao personagem. Só depois deste trabalho é que o ator irá experimentar fisicamente as formas de caminhar, as posturas, os figurinos. Ao experimentar estas possibilidades, pode deixar a intuição (o subconsciente, segundo o diretor-pedagogo russo) escolher o que cabe melhor ao personagem.

Em uma segunda fase, Stanislavski parte das ações físicas. Identificamos aqui dois momentos. No primeiro deles o diretor russo trabalha a partir das ações físicas, porém ainda com uma noção de vida interior do personagem que deve ser preenchida com as emoções do ator. Ele ainda recorre à memória das emoções. Propunha que o ator partisse das ações físicas simples do personagem buscando a veracidade, os detalhes que as tornassem críveis (evitando os 
clichês). Depois disso, ou simultaneamente, o ator deveria trabalhar a memória das emoções através de estímulos interiores e exteriores. Estes estímulos seriam iscas para o ator capturar uma emoção que estaria armazenada em seu arquivo (o subconsciente, de acordo com a teoria psicanalítica). As ações físicas (entendidas como estímulos) também poderiam, segundo o entendimento do diretor-pedagogo, provocar emoções novas que não podem ser controladas, apesar de serem desejáveis. Esta noção está vinculada ao princípio cardeal: "por meio do consciente alcançamos o subconsciente" (STANISLAVSKI, 1988, p. 195).

De acordo com Stanislavski, além de intensidades distintas, as emoções têm qualidades diferentes. Daí a idéia de que o ator precisa ampliar ao máximo este arquivo de emoções. $O$ ator deverá sempre ter uma emoção própria, de sua vida, e que está armazenada, para pôr no lugar da emoção do personagem, por analogia. $O$ ator evoca sensações já provadas. “... esses sentimentos, tirados da nossa experiência real e transferidos para o nosso papel, é que dão vida à peça” (STANISLAVSKI, 1988, p. 184).

Identificamos um segundo momento dentro da segunda fase que coincide com o momento final de sua vida, na década de 30, onde Stanislavski propõe que o ator aproxime-se do personagem exclusivamente a partir das ações físicas críveis, respeitando as circunstâncias dadas da peça. Sua ênfase passa para o que chamava de método das ações físicas. “... descobre, de fato, que encontrar a verdade física do papel é melhor, para nutrir sua verdade interior, do que forçar os sentimentos" (STANISLAVSKI, 1987, p. 12).

Tanto em uma quanto em outra fase o diretor-pedagogo está preocupado em lidar com as emoções do ator e do espectador, entende que as emoções ficam arquivadas no subconsciente; intui que a pessoa é uma entidade interior (espírito, a alma) e exterior (físico).

A teoria de Stanislavski propõe um teatro que lide com emoções experimentadas (ele utiliza a expressão: vivida) no palco (e não emoções representadas). Estamos então falando do teatro enquanto meio de alcançar a catarse: esta é a teoria aristotélica de teatro. O espectador entrega-se à cena, vive a emoção do personagem e atinge a catarse, purifica-se. Está claramente expressa em seus estudos uma teoria psicanalítica de emoção segundo a qual esta “...jorra quando você faz presente um trauma, um acontecimento que ficou conflitando em sua mente e aí você vai jorrar a emoção, e ela primeiro acontece na mente e depois ocorre a convulsão histérica, quer dizer, o corpo reage" (BERTOLINO, 1999). 
De acordo com Marvin Carlson, foi provavelmente no início da década de dez "que Stanislavski passou a se interessar particularmente pelas técnicas destinadas a liberar o poder criativo do subconsciente, e o termo chave 'memória emocional', tirado do psicólogo francês Théodule Ribot, entrou em sua obra” (CARLSON, 1995, p. 314).

Théodule Ribot foi um psiquiatra anterior a Freud. Ribot está na raiz da psicanálise já que esta desdobra da psiquiatria. Para a psicanálise o homem tem um lado profundo que ele não conhece nem controla: o inconsciente. Este seria o eu profundo. Em sua teoria encontramos a noção de pessoa como um eu interior, mental: “...na base da antropologia dele está a idéia de que o homem concreto no mundo é um corpo habitado por um eu. Então o corpo representa, manifesta. O corpo é manifestação do eu interior” ( BERTOLINO, 1999).

Ao investigarmos a obra de Stanislavski, constatamos que sua compreensão do ator, do trabalho do ator e do personagem se fundamentam tanto na psicanálise quanto na filosofia oriental (através de seus conhecimentos do yoga) e na racionalidade religiosa. A religião Ortodoxa o induziu a compreender que o ator deveria trabalhar com seu corpo para que a alma pudesse se manifestar no palco, o yoga o levou a acreditar que o ator deveria trabalhar em função da emissão de irradiações invisíveis e a psicanálise induziu sua compreensão de que seria possível estimular o inconsciente para que este fosse exposto na cena.

\section{Vsevolod Meyerhold (1874- 1942)}

A segunda teoria teatral estudada nesta pesquisa foi a desenvolvida por Vsevolod Meyerhold. Em 1895 Meyerhold ingressou como ator no Teatro de Arte de Moscou, dirigido por Stanislavski. Separou-se da companhia em 1902 por não concordar com o naturalismo e o realismo psicológico. Encontrou inspiração em outras correntes estéticas que destacavam valores puramente formais. Ele desejava uma nova cena, onde o teatro não se igualasse à vida e nem fosse uma seqüência de chavões. Pretendia construir uma cena estilizada, queria devolver ao teatro sua teatralidade, sua convencionalidade. Para isso ele precisava formar um novo ator. Voltou-se para a tradição a fim de encontrar elementos para trabalhar este ator. Entendia que a arte deste profissional era a das formas plásticas no espaço, sendo que a nitidez do gesto, “... a forma está considerada como um valor em si” (MEYERHOLD, 1979, p.72).

Em 1919/20 Meyerhold abdicou do teatro profissional e orientouse para um teatro proletário. Entre 1921/ 22 dedicou-se à tarefa de formar atores e investigar o movimento para a cena, o funcionamento, a mecânica do corpo, apoiado nos preceitos construtivistas de beleza funcional e utilitária. 


\section{Urdimento}

Nesta busca o herdeiro de Stanislavski desenvolveu a teoria da biomecânica. Elaborou exercícios com a finalidade de trabalhar a precisão das ações físicas em cena, desenvolvendo o sentido rítmico. Esta teoria estava fundamentada na reflexologia e no taylorismo ${ }^{2}$. A partir de 1923 seguiu-se a etapa construtivista de Meyerhold, no que diz respeito às suas encenações. Em 1925 ele se aproximou de um novo realismo, abandonando a montagem construtivista, pressionado ou induzido por sucessivas limitações impostas pelo Estado soviético (refletir fielmente a vida cotidiana; prioridade à dramaturgia sobre a encenação; não à arte apolítica). A atividade do governo culminou com a proclamação do realismo socialista como única e verdadeira arte, em 1934. Em 1936 o diretorpedagogo foi condenado, entre outros, como formalista. Ele passou a atacar a política cultural do governo e em 1938 seu teatro foi fechado por decreto.

Este diretor russo entendeu a emoção no trabalho do ator a partir da teoria de William James. O filósofo americano, um dos fundadores do pragmatismo, foi autor da teoria periférica das emoções. Segundo esta teoria, determinada emoção é desdobramento de uma ação: uma pessoa tem medo porque treme ao ver o urso. A emoção "medo" ocorreria em função da ação "tremer". "Suas idéias anunciam a corrente behaviorista" (GRANDE ENCICLOPÉDIA LAROUSSE CULTURAL, 1995).

De acordo com a escola behaviorista, uma das psicologias objetivistas que surgiram em oposição às psicologias subjetivistas (como a psicanálise, por exemplo), todo comportamento pode ser explicado como uma reação motora ou glandular condicionada ligada à influência dos fatores do meio ambiente $\mathrm{e}$ não de elementos inatos. Então toda resposta estaria associada a um estímulo. Pavlov, importante comportamentalista considerado por Meyerhold, está na raiz do behaviorismo (BERTOLINO, 1999). Entende que o homem é um sujeito que se comporta de acordo com estímulos.

O fundamento behaviorista se confirma na teoria de Meyerhold ao observarmos a presença constante da idéia de ação-reação ou estímulo-resposta no que se refere ao trabalho do ator. Impregnado das idéias revolucionárias russas, do materialismo, e buscando uma alternativa à "interiorização" do trabalho do ator proposta por Stanislavski, Meyerhold se apropriou das psicologias objetivistas que despontavam em sua época. Foi com esta base teórica que ele tentou esclarecer o ator e o trabalho do ator.

\section{Antonin Artaud (1896 - 1948)}

Artaud foi contra a subordinação do teatro ao texto dramático. Entendia que diálogo era literatura e que, no ocidente, o que era específico do teatro estava sendo relegado a segundo plano. Sentia "o pensamento

${ }^{2}$ Reflexologia é o estudo científico dos reflexos. Foi o nome dado por Bechterev à sua teoria e por vezes aplicado, por extensão, à teoria de Pavlov. O Taylorismo é um sistema de organização científica do trabalho e do controle dos tempos de execução, estabelecido por F. W. Taylor (GRANDE ENCICLOPÉDIA LAROUSSE CULTURAL, 1995). 


\section{Urdimento}

${ }^{13}$ Diferentemente das revistas digitais, onde aparecem críticas no sentido mais ortodoxo, artigos, ensaios e entrevistas. discursivo como uma barreira ao despertar do espírito aprisionado no corpo" (CARLSON, 1995, p. 379). "Artaud vivera obcecado pela sensação de que as palavras eram incapazes de capturar a vida interior" (CARLSON, 1995 , p. 380$)$.

Duas experiências foram marcantes para a definição da função do teatro para Artaud: uma apresentação do teatro de Bali em Paris (1931) - de onde surge para ele a nova idéia de linguagem teatral, e a convivência, durante alguns meses, com os índios Tarahuamaras (México - 1936), onde tomou contato com os ritos do peyote - o que o impressionou profundamente. Daqui a idéia de arte como magia. Depois de ver a primeira apresentação do teatro de Bali na França, Artaud passou a defender um ator que trabalhasse como se fosse um hieróglifo animado, “elevado à condição de signo" (ARTAUD, 1984, p. 120). Estava buscando uma outra linguagem para atingir a si e aos outros por outro caminho, o caminho da sensibilidade e não da reflexão, uma linguagem que utiliza movimentos, gestos simbólicos, máscaras (expressões do rosto codificadas) harmonias, ritmos, vibrações, qualidades de voz, utilização particular das entonações.

Artaud entendia o homem e, portanto, o ator, como sendo uma entidade externa (corporal) e interna (espiritual). Em função desta sua compreensão ele entendeu que a função o do teatro deveria ser a de “...procurar, por todos os meios, repor em questão não apenas todos os aspectos do mundo objetivo e descritivo externo mas também do mundo interno, quer dizer, do homem considerado metafisicamente” (ARTAUD, 1984, p.117). Sua compreensão da personalidade como uma dualidade "corpo-espírito" lhe permitiu intuir a função do teatro como sendo a de libertar forças, ou ainda, a "liberação do inconsciente comprimido" (ARTAUD, 1984, p. 40). "A perspectiva de Artaud (...) era a de um teatro que pudesse mudar o homem psicologicamente (...) por meio da liberação das forças tenebrosas e latentes em sua alma” (CARLSON, 1995, p.379). Segundo Artaud, o interior, o espírito ou a alma é desconhecido e precisa ser liberado através do corpo. Para isso o corpo deve desenvolver uma linguagem apropriada que permita a "manifestação do interior”. “... o espírito precisa de uma linguagem para produzir suas manifestações” (ARTAUD, 1984, p. 21). Portanto, com Artaud, estamos ainda dentro de uma visão psicanalítica do que seja a personalidade.

Artaud fundamenta sua teoria teatral em uma racionalidade psicanalítica por um lado, expressa quando se propõe a "capturar a vida interior" ou "libertar o inconsciente reprimido" através do teatro, e em uma racionalidade religiosa por outro lado, expressa quando entende que o trabalho do ator esteja em função de “ libertar o espírito aprisionado no corpo”. 


\section{Jerzy Grotowski (1923 - 1999)}

Identificam-se dois momentos mais marcantes no trabalho de Grotowski. O primeiro: Teatro Laboratório de Jerzy Grotowski na Polônia (em Opole / 1959 e em Wroclaw / 1965). Neste momento trabalhavam com texto, mas sem submeter-se a ele. $\mathrm{O}$ texto deveria ter uma forte conotação mitológica e apresentar personagens arquétipos, assim, provocariam o confronto entre o mito coletivo e as experiências pessoais: "Percebi então, claramente, que o mito era ao mesmo tempo uma situação primitiva e um modelo complexo com existência independente na psicologia dos grupos sociais, que inspira comportamentos e tendências do grupo" (GROTOWSKI, 1992, p. 20).

De acordo com Grotowski, para que o confronto entre mito coletivo e experiências pessoais ocorresse, seria preciso um treinamento para o ator. $\mathrm{O}$ diretor polonês propôs então o que ele chamou de w: um processo de eliminação de bloqueios entre os "impulsos interiores" e a "ação exterior" do ator. Os exercícios físicos eram um pretexto para descobrirem o que os impedia de executá-los, a fim de eliminar estas "resistências".

O fundamento psicanalítico Junguiano de sua teoria se confirma pela presença dos conceitos de mito, símbolo, arquétipos, máscara (persona) e inconsciente coletivo. Segundo Carl Jung, o ser humano teria uma prédisposição inata para construir arquétipos que são como uma forma essencial (de uma imagem, uma idéia), primeira, na qual caberiam todas as variações culturais desta imagem ou idéia. Esta forma essencial teria um caráter coletivo por ser humana, isto é, anterior à diferenciação cultural. Esta bagagem essencial estaria acumulada em nosso inconsciente ou eu interior ou ainda eu profundo, de onde o conceito de inconsciente coletivo. Jung define o conceito de persona como sendo a máscara social. Então existiria a pessoa, o que se é na realidade, e a persona, que seria o papel desempenhado por um indivíduo de acordo com as expectativas da sociedade. Ainda de acordo com a teoria psicanalítica de Jung, para entrar em contato com os impulsos e sentimentos íntimos (este inconsciente coletivo) seria preciso não identificar-se com a máscara, distanciar-se dela. Foi o que Grotowski buscou através do teatro, como fica claro quando aborda a elaboração da artificialidade: "presumimos que estas formas já existem, completas, dentro do nosso organismo. Aqui tocamos num tipo de representação que, como arte, está mais próxima das escultura que da pintura" (GROTOWSKI, 1992, p. 34). A pintura seria a soma das cores enquanto a escultura seria uma revelação. $\mathrm{O}$ trabalho do escultor consistiria em eliminar aquilo que esconde a forma, como se ela já existisse dentro do bloco de pedra, revelando-a assim, ao invés de criá-la. Esta idéia está associada ao conceito de auto-revelação, bastante importante em Grotowski. 
Assim como Jung, Grotowski entendia que o caminho para uma pessoa entrar em contato com estes arquétipos, sempre foi nos rituais religiosos, através dos símbolos. Como os rituais desapareceram, o homem não se encontra mais com seus impulsos e acaba ficando com sua vida sem sentido. Daí a necessidade de se criar novos rituais. Grotowski propôs então a criação de um ritual secular moderno: o teatro seria o lugar de retirarmos nossas máscaras sociais e revelarmos nossos impulsos mais secretos, para nós mesmos (atores) e para os outros (platéia), passando ambos pelo mesmo processo de autodesvendamento: "Estamos interessados no espectador que sinta uma genuína necessidade espiritual, e que realmente deseje, através do confronto coma representação, analisar-se” (GROTOWSKI, 1992, p. 35).

O segundo momento no trabalho do diretor polonês delimita-se a partir da década de 70. É o chamado período parateatral. A partir daqui Grotowski pára de relacionar seu teatro com a platéia. Não quer mais "controlar a mente" do espectador. Preocupa-se com o processo interior do atuante, isto é, exclusivamente com a arte como veículo, a arte como meio de auto-conhecimento. A noção do trabalho do ator como implicando uma energia ancestral confirma o fundamento psicanalítico Junguiano de sua teoria, mesmo neste segundo momento de seu processo.

\section{Eugenio Barba (1936)}

Barba ficou três anos na Polônia observando o trabalho de Grotowski, no início dos anos 60. Em 1964 o diretor italiano foi para Oslo e fundou o Odin Teatret. Desejando novas relações entre teatro e sociedade, foram a lugares onde o teatro era desconhecido ou em que se fazia outro tipo de teatro, distinto do europeu, e realizaram as trocas: mostravam seu trabalho e viam alguma manifestação cultural do lugar. Neste movimento foram conhecendo novas possibilidades técnicas para os atores e também outras possibilidades de estruturar a cena. Estudaram com profundidade os grandes mestres do teatro ocidental; interessaram-se pelo que havia em comum entre as diferentes formas de estar no palco, entre as diferentes formas de utilizar o corpo em cena. Estes pontos em comum foram chamados de princípios que retornam. São eles: o princípio da oposição, da omissão, da equivalência e princípio do equilíbrio (precário ou de luxo). Segundo Barba, são estes que garantem o nível físico da presença do ator em cena, ou seja, a pré-expressividade. A partir destes princípios que retornam e destas novas possibilidades de estruturar a cena com as ações, Barba fundamenta seu trabalho com os atores/bailarinos.

A noção de ação-reação está bastante presente em toda a teoria de Barba, e nos leva a identificar um fundamento behaviorista para compreender 
a personalidade, o ator e o trabalho deste: "A emoção é uma reação. Há um estímulo interno ou externo e a reação sob forma de comportamento manifesta uma emoção" (BARBA, 1989, p. 55).

Outro conceito recorrente na teoria teatral deste diretor é o de fluxo de energia: o fluxo de nossa energia, como processo mental e fisiológico, se concretiza nas ações físicas e vocais, afirma Barba. "É essencial proteger o fluxo, este tecido de sons que deve sair sem a vontade de expressar alguma coisa. Não há reflexão, são somente ações vocais" (BARBA, 1989, p. 54). Para pôr em movimento este fluxo de energia, ele desenvolve o treinamento:

O teatro é também um momento no qual a pessoa começa a irradiar energia em um nível diverso daquele da vida cotidiana. Então, automaticamente, esta pessoa atrai, fascina. O teatro é uma questão de energias que atraem (...) No entanto, existem treinamentos que através da atividade física irradiam energia. (...) É necessário contê-la de modo que se crie um dique. O ensaio é o dique, e você pode graduar esta energia para obter o resultado desejado... (BARBA, 1991, p. 74).

Verificamos nesta citação a noção de irradiação da energia, noção já presente na teoria de Stanislavski. Esta noção é própria da filosofia oriental e chegou a Stanislavski através de seus estudos do Yoga, filosofia que considera a dualidade corpo-espírito para compreender o ser humano.

É possível identificar na teoria teatral de Eugenio Barba tanto a utilização de uma fundamentação psicológica behaviorista quanto a apropriação da racionalidade religiosa (que implica a crença sagrada) para esclarecer o ator e o trabalho do ator.

\section{Considerações finais}

É importante a constatação de que estes teóricos do teatro do século XX se dedicaram ao estudo da personalidade, se aproximando de teóricos de seu tempo. Verificamos também que a maioria das teorias teatrais têm uma visão sobre a personalidade como uma dualidade: interior e exterior. Ora este interior é o espírito, a alma, ora o subconsciente, ora o inconsciente coletivo. Destacamos a semelhança entre os fundamentos de Stanislavski, Artaud e Grotowski (psicanálise), paradoxalmente homens de teatro tão opostos em suas abordagens práticas.

Professores, diretores e também atores só têm a ganhar com o estudo das diferentes psicologias, com a identificação destas nas teorias teatrais. Poderão desta forma escolher com lucidez um caminho para compreender tanto a personalidade quanto a emoção e a imaginação relacionados ao trabalho 
do ator. Em períodos de formação, técnicas são aplicadas, exercícios, e muitas vezes este embasamento teórico referente à compreensão da personalidade não está sedimentado. Quando defendemos que professores e diretores deveriam conhecer mais profundamente a área da psicologia, alguns argumentariam que teatro não é terapia. Pensamos que em função desta mentalidade temos mantido uma posição irresponsável com relação a nossos alunos. O que alcançamos se ficamos encerrados em nossa área? A esterilidade. Não seremos terapeutas. Seremos diretores, atores e professores que buscam conhecer o básico, o que qualquer profissional busca: conhecer o material com o qual trabalham.

\section{Referências bibliográficas}

ARTAUD, Antonin. O teatro e seu duplo. São Paulo: Max Limonad, 1984.

BARBA, Eugenio. Além das ilhas flutuantes. Campinas: Hucitec, 1991. - A canoa de papel. São Paulo: Hucitec, 1994.

BERTOLINO, Pedro. Entrevista concedida a Luciana Cesconetto Fernandes da Silva. Florianópolis, jul. 1999.

BOUFFONNERIES. Le théâtre qui danse [O teatro que dança]. Lectoure : Bouffonneries Contrastes, n. 22/23, 1989.

CARLSON, Marvin. Teorias do teatro. São Paulo: Unesp, 1995.

COPEAU, Jacques. Registres I; Appels. [Registros; Apelos]. Paris : Gallimard, 1974.

FREITAS, Paulo Luis de. Tornar-se ator. Uma análise do ensino de interpretação no Brasil. Campinas: Editora da Unicamp, 1998.

GARRET, Henry E. Grandes experimentos da psicologia. São Paulo: Companhia Editorial Nacional, 1966.

GRANDE ENCICLOPÉDIA LAROUSSE CULTURAL, São Paulo: Nova Cultural, 1995.

GROTOWSKI, Jerzy. Em busca de um teatro pobre. $4^{\text {a }}$. ed. Rio de Janeiro : Civilização Brasileira, 1992.

MEYERHOLD, Vsevolod. Teoría teatral.3.ed. Madrid: Editorial Fundamentos, 1979.

PERLS, Fritz. A abordagem gestáltica e Testemunha ocular da terapia. Rio de Janeiro: Guanabara, 1988.

RAEDERS, Georges. O cinquentenário da fundação do "Vieux Colombier". Porto Alegre: Publicação do curso de Arte Dramática da URGS, 1965.

ROUBINE, Jean Jaques. A linguagem da encenação teatral. Rio de Janeiro: Jorge Zahar, 1982. 
SCHULTZ, Duane. História da psicologia moderna. São Paulo: Cultrix, 1975.

SESC. GROTOWSKI. Entrevista concedida a Jean-Pierre Thimbaudat In: Simpósio Internacional "A pesquisa de Jerzy Grotowski e Thomas Richards sobre A Arte como Veículo" organizado pelo Centro de Pesquisa Teatral do SESC, out. 1996.

STANISLAVSKI, Constantin. A preparação do ator. $8^{\text {a }}$. ed. Rio de Janeiro : Civilização Brasileira, 1988.

A construção da personagem. $4^{\mathrm{a}}$. ed. Rio de Janeiro : Civilização Brasileira, 1986. A criação de um papel. $3^{\mathrm{a}}$. ed. Rio de Janeiro : Civilização. Brasileira, 1987.

STORR, Anthony. As idéias de Jung. São Paulo: Cultrix, 1973.

OS PENSADORES. William James. São Paulo: Abril Cultural, 1979. 